\title{
Manajemen dan Rekayasa Lalu Lintas Turn Left Only Circulation pada Perlintasan Sebidang Tirus dengan Software VISSIM
}

\author{
Pipit Rusmandani $^{1}$, Nurul Fitriani ${ }^{2}$, Ema Pratami Rosyada ${ }^{3}$ dan Riandy Sholeh Setiawan ${ }^{4}$ \\ ${ }^{1}$ Politeknik Keselamatan Transportasi Jalan \\ ${ }^{2}$ Politeknik Keselamatan Transportasi Jalan \\ ${ }^{3}$ Politeknik Keselamatan Transportasi Jalan \\ ${ }^{4}$ Dinas Perhubungan Kota Tegal \\ *E-mail: nurulfitriani.mtf@gmail.com
}

\begin{abstract}
Abstrak
Perlintasan Sebidang Tirus dinilai memiliki kinerja yang kurang baik karena sering menimbulkan antrian kendaraan yang cukup panjang serta tundaan cukup lama, sehingga memerlukan penanganan yang dinamis berupa manajeman rekayasa lalu lintas. Penelitian berupa rekayasa lalu lintas dengan penanganan utama berupa turn left only circulation coba diterapkan sebagai solusi untuk menangani permasalahan pada persimpangan tersebut. Tujuan dari penelitian ini adalah untuk mengetahui kinerja eksisting persimpangan serta mengetahui tingkat efektivitas penanganan rekayasa lalu lintas turn left only circulation. Rekayasa lalu lintas dilakukan menggunakan software VISSIM untuk membuat pemodelan serta mengetahui nilai Level of Service (LOS), serta software SSAM untuk mengetahui konflik yang terjadi. Dari hasil analisis didapatkan nilai LOS C pada kondisi eksisting dengan nilai total konflik sebanyak 230. Alternatif I memiliki nilai LOS A dengan nilai total konflik sebanyak 43, Alternatif II memiliki nilai LOS B dengan nilai total konflik sebanyak 49 serta alternatif III memiliki nilai LOS A dengan nilai total konflik sebanyak 47. Alternatif I dianggap sebagai opsi penangan jangka pendek yang tepat karena memiliki nilai LOS A serta jumlah konflik paling kecil dan hanya membutuhkan koordinasi terkait jalan dan simpang lain yang terdampak. Sedangkan alternatif III dianggap cocok sebagai opsi penanganan jangka menengah karena meski memiliki nilai LOS A dan konflik yang cukup rendah, namun masih memerlukan upaya penanganan lain berupa pembebasan lahan untuk pelebaran jalan.
\end{abstract}

Kata kunci: Persimpangan Sebidang Tirus, Manajemen Rekayasa Lalu Lintas, Turn Left Only Circulation, VISSIM, SSAM.

\section{A. PENDAhuluan}

Salah satu perlintasan sebidang di Kota Tegal yang dinilai memiliki kinerja yang kurang baik adalah perlintasan sebidang Tirus. Perlintasan yang mempertemukan jalur kereta dengan arus lalu lintas dari 3 (tiga) arah yaitu dari Jl. KS Tubun, Jl. Kapten Sudibyo serta Jl. Teuku Umar ini menimbulkan antrian yang cukup panjang serta tundaan pada saat pintu perlintasan ditutup. Tidak hanya saat pintu perlintasan ditutup, namun juga berlanjut pada saat pintu perlintasan dibuka dan kondisi ini sering mengakibatkan terjadinya kemacetan.

Berdasarkan permasalahan tersebut, telah banyak upaya dari para peneliti untuk memberikan kajian-kajian dalam mengatasi kemacetan yang terjadi pada perlintasan sebidang Tirus ini. Selain itu, Pemerintah Kota Tegal juga menargetkan pembangunan fly over (jalan layang) pada persimpangan tersebut. Target pembangunan fly over tersebut sangatlah tepat, karena sejalan dengan Peraturan Menteri Perhubungan Republik Indonesia Nomor PM 94 Tahun 2018 terkait rekomendasi peningkatan status perlintasan sebidang menjadi perlintasan tidak sebidang. Namun sejauh ini, rencana tersebut belum dapat terealisasi karena beberapa hal. Oleh karena itu, sebagai rekomendasi penanganan jangka pendek permasalahan tersebut, diperlukan adanya langkah yang tepat berupa manajemen rekayasa lalu lintas yang dinamis. Alternatif rekayasa lalu lintas dengan penanganan utama berupa turn left only circulation coba diterapkan sebagai solusi untuk menangani permasalahan pada persimpangan tersebut dengan beberapa perlakuan tambahan.

Penelitian ini memiliki tujan sebagai berikut:

1. Mengetahui Kinerja Eksisting persimpangan pada perlintasan sebidang Tirus Kota Tegal.

2. Mengetahui bagaimana tingkat efektifitas penerapan rekayasa lalu lintas turn left only circulation pada 
perlintasan sebidang pada perlintasan sebidang Tirus Kota Tegal.

\section{B. METODE}

Penelitian ini menggunakan dua jenis data yaitu data primer dan data sekunder. Data Primer didapatkan dengan melakukan pengamatan dan survei secara langsung. Sedangkan data sekunder didapatkan dari website instansi terkait.

1. Kondisi Geometrik

Data ini diperoleh dengan melakukan survei secara langsung di lapangan dengan mengamati dan mengukur bagian jalan di titik lokasi penelitian. Data ini merupakan data awal yang diambil untuk mengetahui kondisi eksisting pada lokasi penelitian.

2. Volume lalu lintas

Volume lalu lintas didapatkan dengan melakukan survei pada simpang Tirus dengan menggunakan alat hitung (counter). Volume kendaraan yang masih dalam satuan kendaraan per jam (kend/jam) harus dikalikan terlebih dahulu dengan nilai ekivalen mobil penumpang (emp) agar menjadi satuan mobil penumpang (smp/jam) menggunakan rumus (1) .

$Q s m p=(e m p L V \times L V+e m p H V \times H V+e m p M C \times M C)$

Sumber: MKJI (1997)

3. Kecepatan Kendaraan

Pengambilan data kecepatan dilakukan menggunakan alat speedgun. Maksud dari dilaksanakannya survei ini adalah untuk mengetahui kecepatan kendaraan pada saat melintas pada persimpangan. Selanjutnya data ini akan dianalisa menggunakan metode kecepatan 85 persentil. Kecepatan 85 persentil adalah sebuah kecepatan lalu lintas dimana $85 \%$ dari pengemudi mengemudikan kendaraannya di jalan tanpa dipengaruhi oleh kecepatan lalu lintas yang lebih rendah atau cuaca yang buruk untuk menentukan batas kecepatan yang ideal pada ruas jalan (Kawulur et al, 2013).

4. Analisis dengan Software VISSIM dan SSAM

Setelah data dari lapangan diolah, kemudian dilanjutkan dengan melakukan analisis menggunakan software VISSIM dan SSAM. VISSIM merupakan simulasi mikroskopis berdasarkan waktu dan perilaku yang dikembangkan untuk model lalu lintas perkotaan. Program ini dapat digunakan untuk menganalisa operasi lalu lintas di bawah batasan konfigurasi garis jalan, komposisi lalu lintas, tempat perhentian, dll. VISSIM digunakan untuk mendapatkan nilai level of service (LOS) dari LOS_A sampai LOS_F dengan ketentuan rentang nilai tundaan seperti pada Tabel 1.

Tabel 1 Level of Service (LOS)

\begin{tabular}{cl}
\hline LOS & \multicolumn{1}{c}{ Tundaan } \\
\hline LOS_A & $<10 \mathrm{~s}$ \\
\hline LOS_B & $>10 \mathrm{~s}-15 \mathrm{~s}$ \\
\hline LOS_C & $>15 \mathrm{~s}-25 \mathrm{~s}$ \\
\hline LOS_D & $>25 \mathrm{~s}-35 \mathrm{~s}$ \\
\hline LOS_E & $>35 \mathrm{~s}-50 \mathrm{~s}$ \\
\hline LOS_F & $>50 \mathrm{~s}$ \\
\hline Sumber: PTVAG(2018) &
\end{tabular}

Hasil dari simulasi menggunakan software VISSIM kemudian dianalisis dengan software SSAM. Surrogate Safety Assessment Model ( SSAM ) merupakan suatu metode yang menggabungkan antara mikrosimulasi dan analisis konflik secara otomatis serta menganalisis frekuensi dan karakter dari tipe konflik antar kendaraan pada suatu arus lalu lintas yang digunakan untuk menilai keselamatan lalu lintas tanpa menunggu jumlah kecelakaan dan cedera benar-benar terjadi. Program SSAM dapat mengetahui beberapa hasil dari output data VISSIM yaitu dengan format trj yang mampu menunjukkan total konflik yang terjadi diantaranya adalah crossing dan lane change (Rusmandani et al, 2020).

\section{HASIL DAN PEMBAHASAN}

Hasil

1. Kondisi Geometrik

Perlintasan Tirus merupakan simpang tiga dengan adanya perlintasan sebidang rel kereta api. Perintasan ini merupakan jalur utama yang menghubungkan Kota Tegal dengan daerah sekitarnya seperti Kabupaten Tegal dan merupakan penghubung jalur selatan Jawa. Adapun kondisi eksisiting geometrik pada Persimpangan Sebidang Tirus adalah sebagai berikut: 
a. Gradien kemiringan perlintasan $>5 \%$

b. Persilangan Tidak Tegak Lurus

c. Crossing Belok Kanan

d. Lebar Jalan :
1) Kapten Sudibyo = $=14 \mathrm{~m}$, tidak bermedian
2) KS. Tubun $\quad=10 \mathrm{~m}$, tidak bermedian
3) Teuku Umar $=8 \mathrm{~m}$, tidak bermedian

2. Volume Lalu Lintas

Survai Volume Lalu Lintas pada simpang Tirus dilakukan selama satu hari dari jam 06.00 sampai jam 18.00. Untuk waktu penghitungan per satu jam dapat dilihat pada Gambar 1.

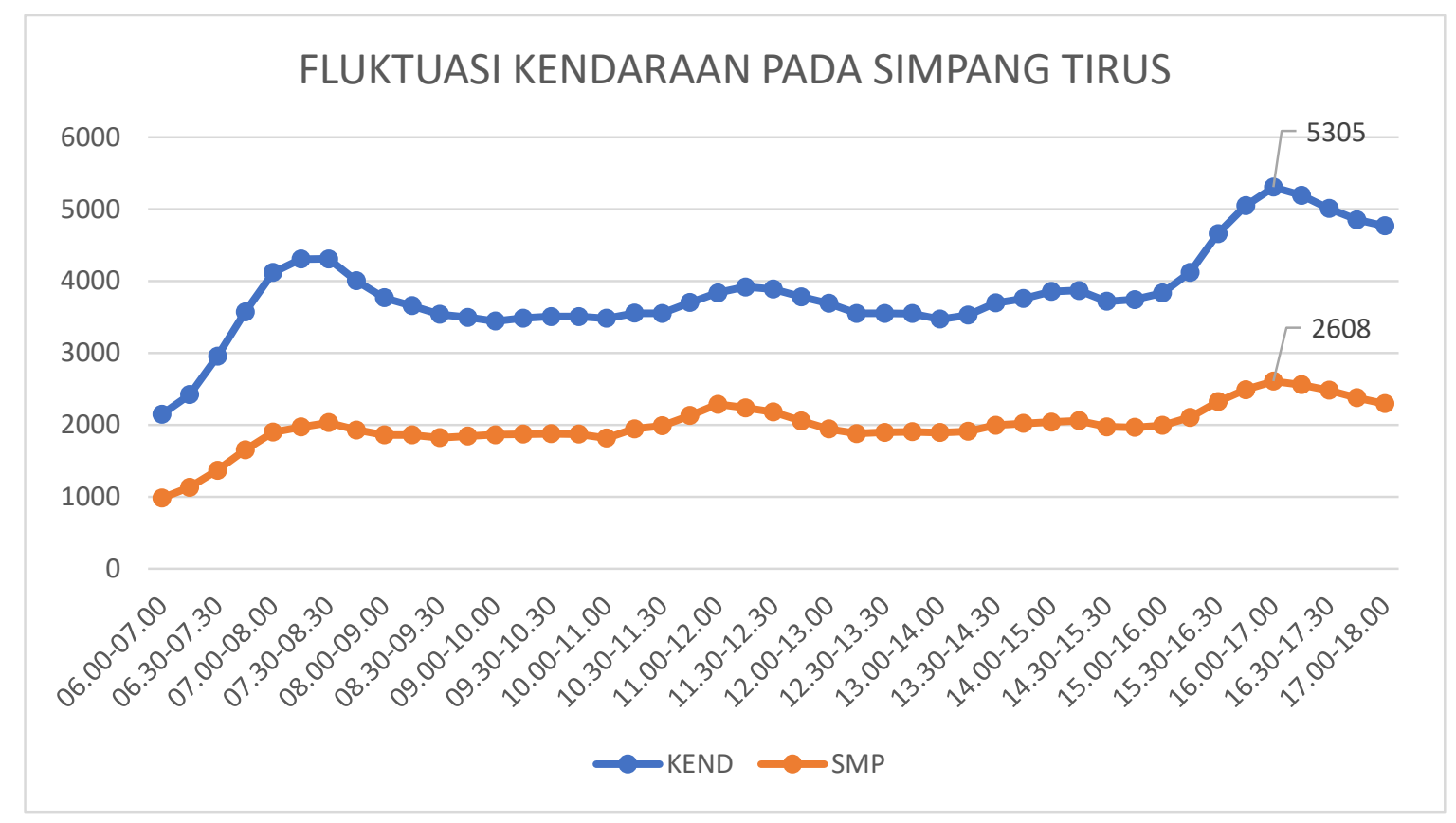

Gambar 1 Fluktuasi Kendaraan pada Simpang Tirus (Analisis Peneliti, 2020)

Grafik pada Gambar 2 menunjukkan bahwa jam puncak terjadi pada jam 16.00-17.00 dengan kendaraan yang melintas sebanyak $5.305 \mathrm{kend} / \mathrm{jam}$ dan satuan mobil penumpang $2.608 \mathrm{smp} / \mathrm{jam}$.

3. Kecepatan Kendaraan

Hasil survei kecepatan kendaraan yang telah diolah dengan metode kecepatan 85 persentil (P85) dapat dilihat pada Gambar 2, Gambar 3 dan Gambar 4.
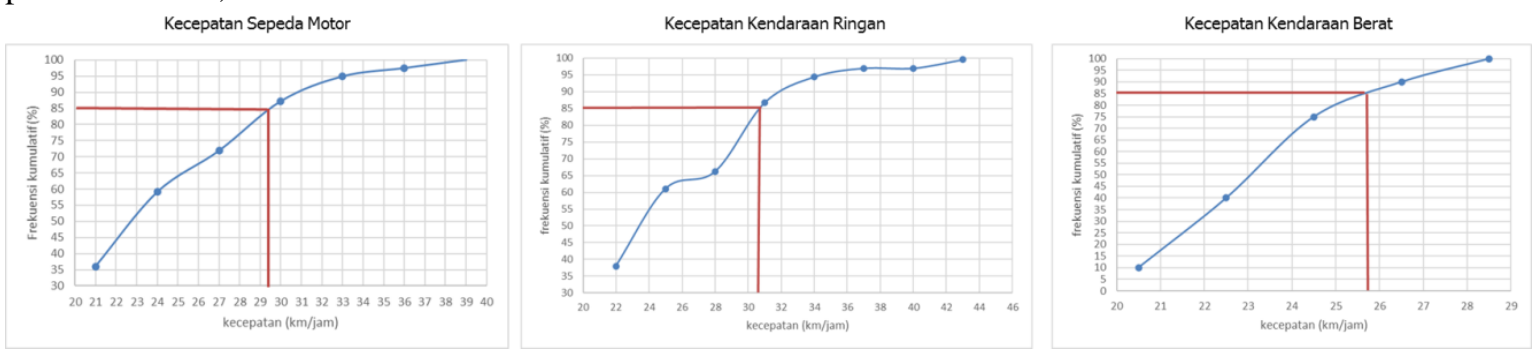

Gambar 2 Kecepatan 85 Persentil pada Jl. Teuku Umar (Analisis Peneliti, 2020)

Grafik pada Gambar 2 menunjukkan bahwa kecepatan kendaraan yang melintas pada ruas Jl. Teuku Umar yaitu $29 \mathrm{~km} / \mathrm{jam}$ untuk sepeda motor, $30 \mathrm{~km} / \mathrm{jam}$ untuk kendaraan ringan dan $26 \mathrm{~km} / \mathrm{jam}$ untuk kendaraan berat. 

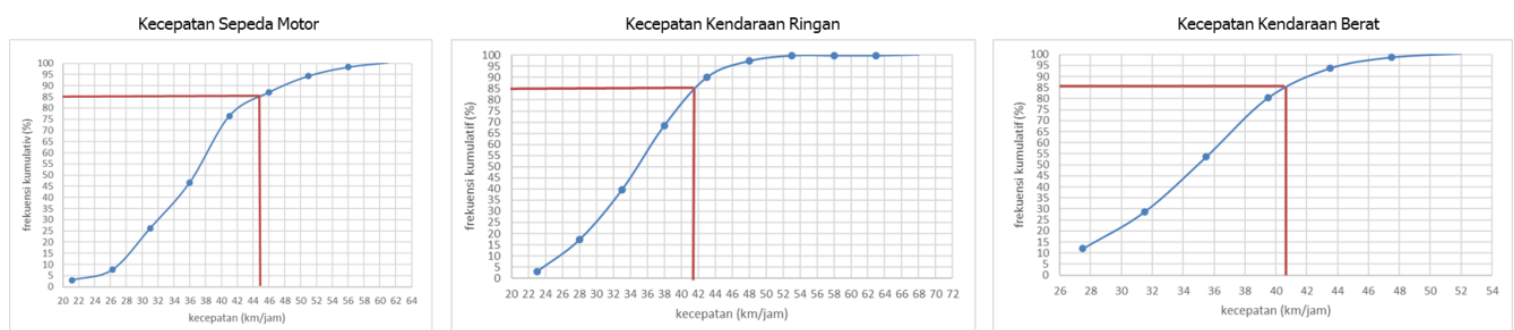

Gambar 3 Kecepatan 85 Persentil pada Jl. KS. Tubun (Analisis Peneliti, 2020)

Grafik pada Gambar 3 menunjukkan bahwa kecepatan kendaraan yang melintas pada ruas Jl. KS Tubun yaitu $45 \mathrm{~km} / \mathrm{jam}$ untuk sepeda motor, $41 \mathrm{~km} / \mathrm{jam}$ untuk kendaraan ringan dan $40 \mathrm{~km} / \mathrm{jam}$ untuk kendaraan berat.
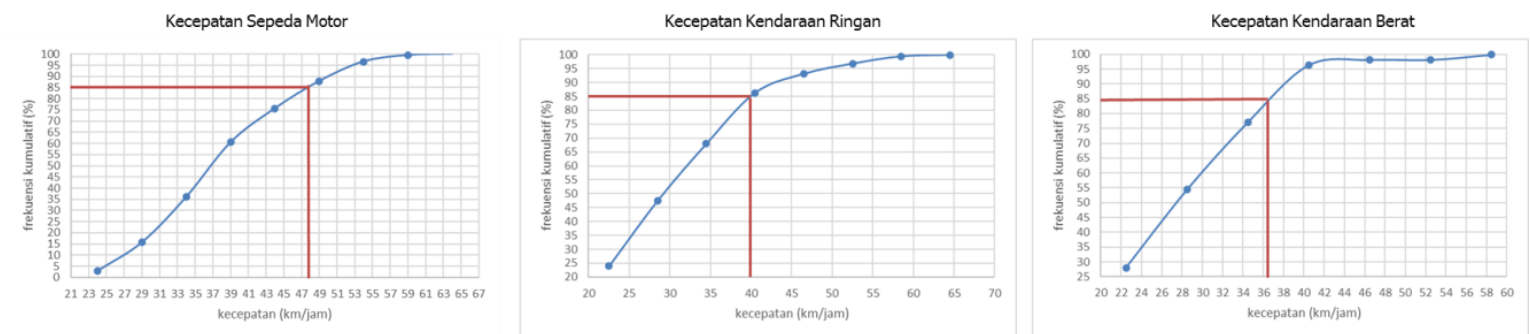

Gambar 4 Kecepatan 85 Persentil pada J1. Kapten Sudibyo (Analisis Peneliti, 2020)

Grafik pada Gambar 4 menunjukkan bahwa kecepatan kendaraan yang melintas pada ruas Jl. Kapten Sudibyo yaitu $48 \mathrm{~km} / \mathrm{jam}$ untuk sepeda motor, $40 \mathrm{~km} / \mathrm{jam}$ untuk kendaraan ringan dan $36 \mathrm{~km} / \mathrm{jam}$ pada kendaraan berat.

4. Skematik Penanganan Persimpangan

Kondisi eksisting persimpangan sebidang tirus mempunyai karakter lalu lintas percabangan dengan diperbolehkannya perjalanan ke kanan dan kiri dari dan ke segala arah seperti pada Gambar 5 (a) menyebabkan sering terjadi kemacetan pada persimpangan tersebut. Untuk menangani kemacetan yang sering terjadi, dibuatlah 3 skema penanganan yaitu: Alternatif I berupa rekayasan lalu lintas dengan semua pergerakan hanya belok kiri tanpa terkecuali, seperti terlihat pada Gambar 5 (b); Alternatif II diskemakan dengan pergerakan hanya belok kiri akan tetapi memberikan kesempatan putar balik/U-Turn untuk kendaraan pribadi dan sepeda motor pada kaki simpang serta menambahkan median di Jl. Teuku Umar dan Jl. KS Tubun, seperti yang terlihat pada Gambar 5 (c); Alternatif III yaitu tetap dengan rekayasa lalu lintas hanya belok kiri, memberikan kesempatan putar balik/U-Turn untuk kendaraan pribadi dan sepeda motor pada kaki simpang serta menambahkan median di Jl. Teuku Umar dan Jl. KS Tubun namun juga menambahkan rencana perlebaran jalan dari kondisi lebar ekisting Jl. KS Tubun 10 meter menjadi 16 meter dan pada Jl. Tengku Umar yang awalnya 8 meter menjadi 16 meter, sebagaimana terlihat pada Gambar 5 (d).
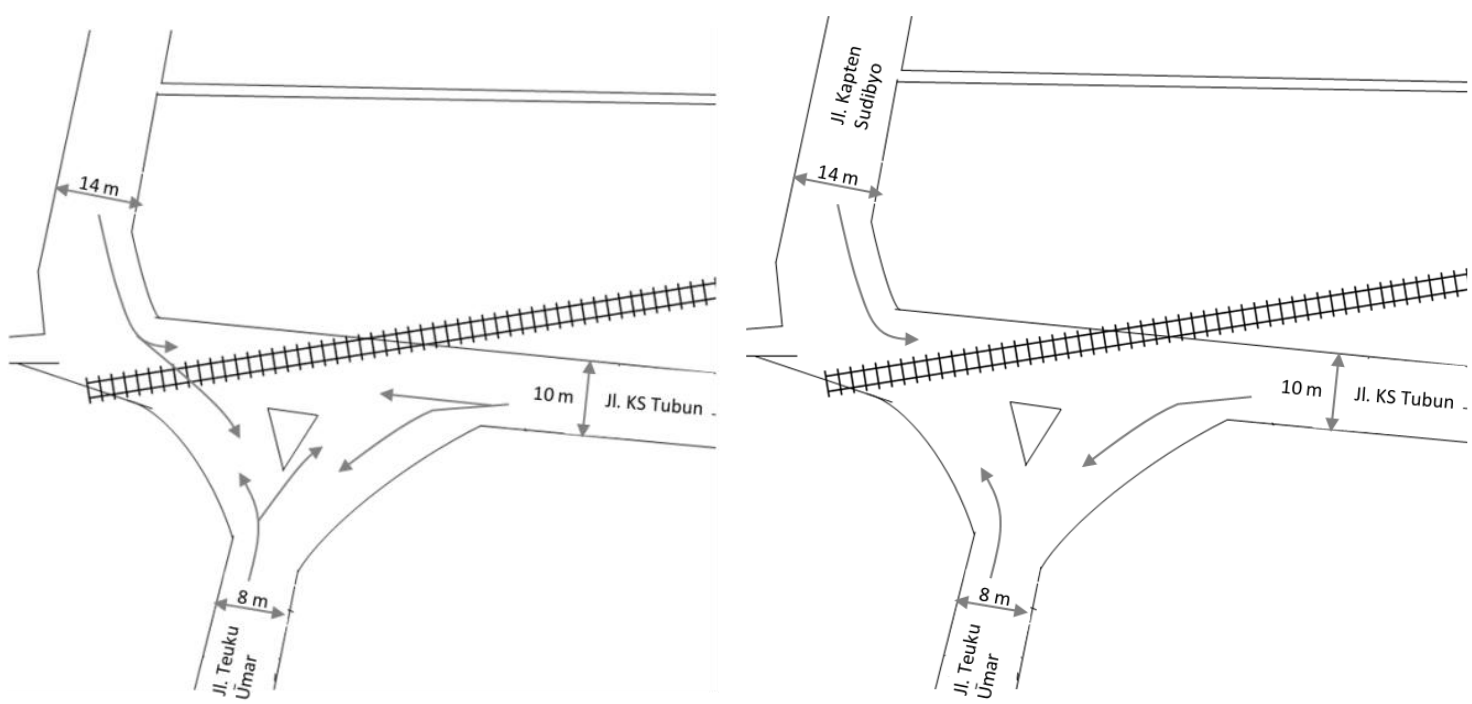
(a)

(b)

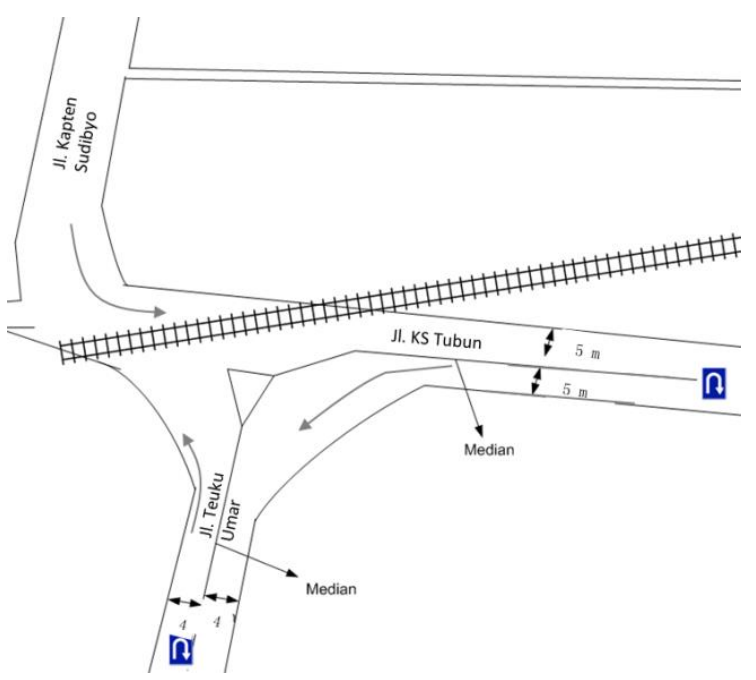

(c)

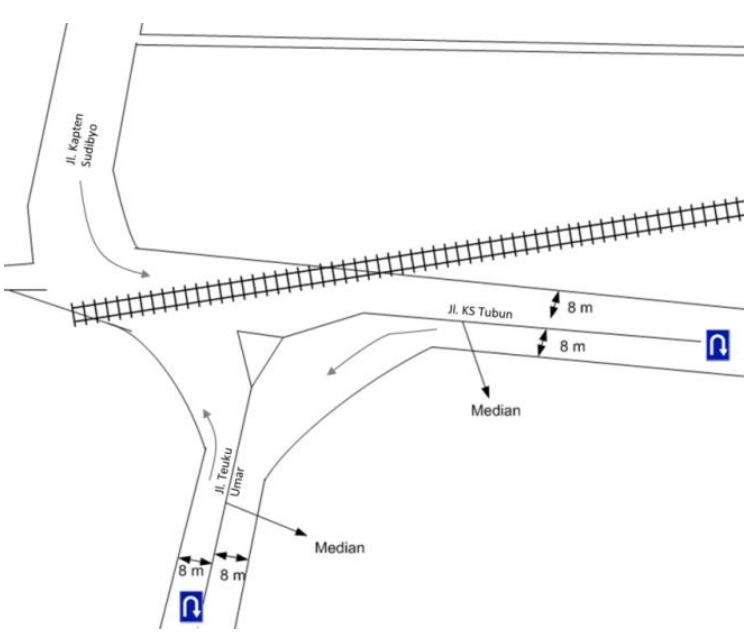

(d)

Gambar 5 Pergerakan Lalu lintas di Persimpangan Sebidang Tirus (a)Eksisting; (b)Alt I; (c)Alt II; (d)alt III

5. Analisis dengan Software VISSIM dan SSAM.

Langkah - langkah pemodelan simulasi persimpangan diawali dengan membuat network model yang disesuaikan dengan kondisi geometrik dan kondisi lalu lintas (jalan raya dan rel) di lapangan. Dalam penggunaan model harus dilakukan kalibrasi dan validasi, hal ini bertujuan untuk memastikan hasil simulasi dalam VISSIM sesuai dengan kondisi di lapangan.

a. Kalibrasi simulasi VISSIM

Kalibrasi pada model VISSIM berfungsi untuk menilai kesesuaian antara model simulasi dan model observasi agar dapat menghasilkan output yang sesuai dengan realita di lapangan dengan cara mengatur parameter perilaku mengemudi (driving behavior). Pada tabel 2 menunjukan bahwa kaliberasi model VISSIM dilakukan dengan 3 (tiga) kali percobaan yakni default, trial 1 dan trial 2.

Tabel 2 Kalibrasi VISSIM

\begin{tabular}{|c|c|c|c|}
\hline \multirow{2}{*}{$\begin{array}{c}\text { Trial Ke } \\
-\end{array}$} & \multirow{2}{*}{ Parameter yang diubah } & \multicolumn{2}{|c|}{ Nilai } \\
\hline & & Sebelum & Sesudah \\
\hline \multirow[t]{2}{*}{ Default } & Desired position at free flow & Middle of lane & Middle of lane \\
\hline & Overtake on same lane left \& on right & off & Off \\
\hline \multirow[t]{2}{*}{1} & Desired position at free flow & Middle of lane & any \\
\hline & Overtake on same lane left \& on right & off & On \\
\hline \multirow[t]{3}{*}{2.} & Average standstill distance & 2 & 0,5 \\
\hline & Additive part of safety distance & 2 & 0,5 \\
\hline & Multiplicative part safety distance & 3 & 1 \\
\hline
\end{tabular}

b. Validasi Model

Validasi dilakukan untuk mengukur ketepatan simulasi model dan parameter yang sudah diatur sebelumnya. Pada perhitungan validasi model ini menggunakan rumus Geoffey E. Harvers 9 (GEH). Dengan ketentukan apabila GEH $<5,0$ maka model simulasi dinyatakan diterima atau valid, begitu juga sebaliknya. Hasil uji GEH seperti terlihat pada Tabel 3.

Tabel 3 Hasil Uji GEH Volume Lalu Lintas 


\begin{tabular}{cllcccc}
\hline \multirow{2}{*}{ Trial ke- } & \multicolumn{1}{c}{ Parameter } & $\begin{array}{c}\text { Hasil } \\
\text { Survei }\end{array}$ & Model & GEH & MAPE & Keterangan \\
\hline \multirow{3}{*}{ Default } & Teuku Umar & 1440 & 1026 & 138.93 & 0.287 & Ditolak \\
\cline { 2 - 7 } & Kapten Sudibyo & 1464 & 1310 & 17.20 & 0.106 & Ditolak \\
\cline { 2 - 7 } & KS.Tubun & 1567 & 1131 & 140.84 & 0.278 & Ditolak \\
\hline \multirow{2}{*}{1} & Teuku Umar & 1440 & 1434 & 0.03 & 0.004 & Diterima \\
\cline { 2 - 7 } & Kapten Sudibyo & 1464 & 1464 & 0.00 & 0.000 & Diterima \\
\cline { 2 - 7 } & KS.Tubun & 1567 & 1526 & 1.08 & 0.026 & Diterima \\
\hline \multirow{2}{*}{2} & Teuku Umar & 1440 & 1434 & 0.03 & 0.004 & Diterima \\
\cline { 2 - 7 } & Kapten Sudibyo & 1464 & 1464 & 0.00 & 0.000 & Diterima \\
\cline { 2 - 7 } & KS.Tubun & 1567 & 1561 & 0.03 & 0.004 & Diterima \\
\hline
\end{tabular}

Hasil uji GEH terkait volume lalu lintas pada simulasi masing - masing pendekat Jalan menunjukkan nilai GEH $<5,0$. Oleh karenanya, dapat disimpulkan bahwa dengan mengubah parameter-parameter yang disebutkan pada Tabel 2, maka pemodelan simulasi dinyatakan valid dan sesuai dengan kondisi arus lalu lintas di lapangan.

c. Penentuan Nilai Kinerja Persimpangan dengan VISSIM

Kinerja dari sebuah persimpangan dapat dilihat dari nilai LOS yang didasarkan pada nilai vehicle delay. Berdasarkan pengolahan data dengan menggunakan software VISSIM didapatkanlah nilai kinerja eksisting dan penanganan seperti pada Tabel 4. Kondisi eksisting Persimpangan Tirus yaitu ada pada kategori LOS C dengan panjang antrian 29,33 meter dan tundaan selama 23,5 detik. Sedangkan Kinerja lalu lintas untuk alternatif penangan yaitu: Alternatif I ada pada katagori LOS A dengan antrian sepanjang 14,53 meter serta tundaan selama 8,81 detik; alternatif II ada pada katagori LOS B dengan antrian sepanjang 6,75 meter serta tundaan selama 11,61 detik; serta alternatif III ada pada katagori LOS A dengan antrian sepanjang 2,77 meter serta tundaan selama 6,09 detik.

Tabel 4 Kinerja Persimpangan Tirus

\begin{tabular}{clclc}
\hline Time Interval & Penanganan & Qlenght & LOS & Vehicle Delay \\
\hline $0-3600$ & Eksisting & 29,33 & LOS_C & 23,50 \\
\hline $0-3600$ & Alternatif I & 14,53 & LOS_A & 8,81 \\
\hline $0-3600$ & Alternatif II & 6,75 & LOS_B & 11,61 \\
\hline $0-3600$ & Alternatif III & 2,77 & LOS_A & 6,09 \\
\hline
\end{tabular}

Sumber: Analisis Peneliti (2020)

d. Evaluasi Konflik Persimpangan dengan SSAM

Perhitungan konfik lalu lintas dilakukan dengan software SSAM dari hasil pengolahan data VISSIM berupa file trj.

Tabel 5 Konflik Lalu Lintas

\begin{tabular}{lcccc}
\hline \multicolumn{1}{c}{ JENIS KONFLIK } & EKSISTING & ALT 1 & ALT 2 & ALT 3 \\
\hline Crossing & 215 & 23 & 44 & 34 \\
\hline Lane change & 15 & 20 & 5 & 13 \\
\hline Total & 230 & 43 & 49 & 47 \\
Sumber: Analisis Peneliti $(2020)$ & & &
\end{tabular}

Adapun hasil pengolahan dapat dilihat pada Tabel 5 yaitu: pada kondisi eksisting terjadi konflik crossing sebanyak 215 kejadian dan konflik lane change sebanyak 15 kejadian; Alternatif I terjadi konflik crossing 23 kejadian dan konflik lane change 30 kejadian; Alternatif II terjadi konflik crossing 44 kejadian dan konflik lane change 5 kejadian; Alternatif III terjadi konflik crossing sebanyak 34 dan konflik lane change 13 kejadian.

\section{Pembahasan}

Berdasarkan hasil analisis seperti pada Tabel 4, terlihat bahwa kinerja dari semua alternatif penanganan jauh lebih baik jika dibandingkan dengan kondisi eksisting. Dimana terdapat penurunan panjang antrian sebesar 50,4\% pada alternatif I, 76,9\% pada alternatif II dan 90,5\% pada alternatif III serta terjadi penurunan tundaan sebesar $62,5 \%$ pada alternatif I, 50,6\% pada alternatif II dan 74,1\% pada alternatif III. Jika alternatif I dibandingkan dengan alternatif II dimana alternatif I dilakukan skema rekayasa lalu lintas semua kendaraan hanya belok kiri langsung dan alternati II berupa skema rekayasa lalu lintas yang sama dengan alternatif I namun juga memberikan kesempatan putar balik/U-Turn untuk kendaraan pribadi dan sepeda motor pada kaki simpang serta menambahkan 
median di Jl. Teuku Umar dan Jl. KS Tubun diketahui bahwa antrian alternatif I lebih panjang dari alternatif II, namun nilai tundaan alternatif I lebih renadah dari nilai tundaan alternatif II. Berdasarkan nilai tersebut diperoleh nilai LOS A pada Alternatif I dan nilai LOS B pada Alternatif II. Melihat perbandingan Alternatif I dan Alternatif II, penanganan dengan turn left only circulation cukup memperbaiki kinerja simpang, namun jika ditambahkan dengan U-Turn tidak menambah kinerja dari persimpangan.

Perbandingan antara alternatif I dengan alternatif III, dimana alternatif III mempunyai skema penanganan sama dengan alternatif II namun dilakukan perubahan geometrik berupa pelebaran ruas jalan. Secara kinerja persimpangan sangat terlihat yaitu alternatif III jauh lebih baik meskipun sama-sama mempunyai nilai LOS A karena nilai antrian dan tundaaan jauh lebih kecil dari alternatif I. Kedua alternatif ini sama-sama dapat dipergunakan. Dalam hal pengguanaa alternatif I, langkah selanjutnya dapat dikoordinasikan dengan wilayah sekitarnya untuk pergerakan lalu lintas, terutama dengan Kabupaten Tegal karena tipe perjalan di Simpang Tirus ini lebih ke perjalanan menerus. Sedangkan pada alternatif III yang dianggap paling efektif masih memerlukan pelebaran jalan dan radius simpang. Alternatif ini bisa digunakan pada jangka menengah karena harus melakukan pembebasan lahan untuk pelebaran jalan.

Selain dari kinerja simpang, konflik lalu lintas yang terjadi juga harus menjadi pertimbanga dalam sebuah tatanan lalu lintas. Setelah dilakukan analisis dengan III alternatif penanganan, maka didapatkan perubahan berupa penurunan jumlah total konflik yang cukup signifikan yaitu penurunan konflik sebesar 81,3\% pada alternatif I, $78,7 \%$ pada alternatif II dan 79,5\% pada alternatif III, untuk lebih jelasanya dapat dilihat pada Tabel 5. Dilihat dari total kejadian konflik lalu lintas, rekayasa lalu lintas aternatif I merupakan kondisi paling dapat mengendalikan jumlah konfik pada persimpangan sebidang Tirus dengan jumlah konflik crossing sebanyak 23 dan konflik lane change 20.

\section{SIMPULAN}

Berdasarkan analisis menggunakan software VISSIM dan SSAM, dapat disimpulkan bahwa kinerja eksisting perlintasan sebidang Tirus ada pada nilai LOS C yaitu arus lalu lintas masih pada kondisi stabil namun kecepatan perjalanan dan kebebasan bergerak sudah dipengaruhi oleh besarnya volume lalu lintas, sehingga pengemudi tidak dapat lagi memilih kecepatan yang diinginkan. Selain itu terdapat 215 konflik crossing dan 15 konflik lane change yang terjadi. Sedangkan untuk alternatif-alternatif penanganan rekayasa lalu lintas dengan rekayasa utama berupa turn left only circulation dianggap cukup merubah kondisi kinerja eksisting yaitu dari LOS C menjadi LOS A dan LOS B serta mampu mengurangi nilai konflik yang terjadi. Alternatif I dianggap sebagai opsi penangan jangka pendek yang tepat karena memiliki nilai LOS A serta jumlah total konflik paling kecil yaitu 43 kejadian dan hanya membutuhkan koordinasi terkait jalan dan simpang lain yang terdampak. Sedangkan alternatif III dianggap cocok sebagai opsi penanganan jangka menengah karena meski memiliki nilai LOS A dan konflik yang cukup rendah yaitu 47 kejadian, namun masih memerlukan upaya penanganan lain berupa pembebasan lahan untuk pelebaran jalan.

\section{REFERENSI}

1. Direktorat Jenderal Bina Marga. (1997). Manual Kapasitas Jalan Indonesia (MKJI)1997. Departeman Pekerjaan Umum. Jakarta.

2. Hartono. (2016). Perlintasan Sebidang Kereta Api di Kota Cirebon Level Crossing Railways in Cirebon. In: Jurnal Penelitian Transportasi Darat,Vol. 18. No.1.

3. Kawulur, C.I., Sendow, T.K., Lintong, E, and Rumayar, A. L. E. (2013). Anlisa Kecepatan yang Diinginkan Oleh Pengemudi. In: Jurnal Sipil Statik, Vol.1. No.4.

4. Peraturan Menteri Perhubungan Republik Indonesia Nomor PM 94 Tahun 2018 tentang Peningkatan Keselamatan Perlintasan Sebidang antara Jalur Kereta Api dengan Jalan

5. PTV AG. (2018). PTV VISSIM 10 User Manual. PTV AG. Karslruhe German.

6. Rusmandani, P., Anggana, E.P., and Sasmito, A. (2020). Mikrosimulasi Kinerja Simpang Bersinyal dengan Menggunakan Software Surrogate Safety Assessment Model (SSAM) di Kota Malang. In: Jurnal Rekayasa Sipil, Vol. 14. No. 2. 